\title{
Constructing Quality Feedback to the Students in Distance Learning: Review of the Current Evidence with Reference to the Online Master Degree in Transplantation
}

\author{
Ahmed Halawa ${ }^{1 \& 2, *}$, Ajay Sharma ${ }^{2 \& 3}$, Julie M Bridson², Sarah Lyon², Denise Prescott ${ }^{2}$, Arpan Guha $^{2 \& 3}$ \& David \\ Taylor ${ }^{2}$ \\ ${ }^{1}$ Sheffield Teaching Hospitals, Sheffield, UK \\ ${ }^{2}$ Faculty of Health and Life Science, Institute of Learning and Teaching, University of Liverpool, UK \\ ${ }^{3}$ Royal Liverpool University Hospitals, Liverpool, UK \\ *Correspondence: Consultant Transplant Surgeon, Sheffield Teaching Hospitals, Herries Road - Sheffield S5 7AU, \\ UK. Tel: 44-778-754-2128. E-mail: ahmed.halawa@sth.nhs.uk
}

Received: June 10, 2017

Accepted: July 17, 2017 Online Published: August 25, 2017

doi:10.5430/wje.v7n4p117

URL: https://doi.org/10.5430/wje.v7n4p117

\begin{abstract}
Introduction: It was a challenge to design a feedback pathway for distance learning course that deals with complex and ambiguous clinical subject like organ transplantation. This course attracts mature clinicians $(\mathrm{n}=117$ spread over three modules) from 27 countries where in addition to the time and zone barriers; there are cultural, institutional background and also ethnic barriers. In addition to the challenges faced in designing the curriculum and assessment that match this diverse group of students, we have to deliver a quality feedback to achieve our leaning objective. How would we construct and deliver this feedback to students you have not seen (in a virtual classroom) and may be on a different continent of this busy planet?

Methods: We analysed the published data on feedback with reflection on the nature of this course and the pedagogy used while considering the diversity of the students joined this course

Conclusion: In this distance-learning course constructing a quality feedback to the students is more technically demanding compared to a traditional course. Students in distance learning need much more support and feedback than in a traditional course. There is a potential threat that these students feel isolated in their own online world and may not engage with this virtual educational environment properly.
\end{abstract}

Keywords: feedback; distance learning; online master degree; transplantation

\section{Introduction}

"A teacher has the distinct responsibility to nurture a student's learning and to provide feedback in such a manner that the student does not leave the classroom feeling defeated" (Reynolds 2007).

We are strongly convinced that a structured feedback is the backbone of formative assessment for the distance-learning course in transplantation launched in 2015 by the University of Liverpool, a member of Russell group. In other words, formative assessment will lose it educational value without a well-designed feedback mechanism.

Many trainers (including ourselves before teaching on this course) have wrong believes that the formative feedback is not needed when there are no areas of concern to be addressed, the coursework was well done, and there are no needs for any further improvement 'everything is OK.' Students appreciate the feedback, especially when it comes from experienced tutors who they respect and see them as role models for their attitudes, knowledge and clinical competence. Reluctance to provide feedback, in itself, sends a wrong message and can lead to wrong interpretation and inappropriate refection by the students on their performance, and also missing a good opportunity to motivate the students (McKimm, 2009).

McKimm (2009) defined the role of feedback in few words; "Feedback is a vital part of education and training which, 
if carried out well, helps to motivate and develop learners' knowledge, skills, and behaviours. It helps students to maximize their potential and professional development at different stages of training, raise their awareness of strengths and areas for improvement, and identify actions to be taken to improve performance" (p.158).

We had asked ourselves when we designed this course how we would give feedback and would this feedback differ from that given in a traditional face-to-face education?

Feedback based on observable behaviour carries more weight and credibility to the students (Gordon, 2003). Ramsden (1992) suggested, "there is no sharp dividing line between assessment and teaching in the area of giving feedback on learning" (p.193), implying that feedback cannot be isolated from the building blocks of education. I agree with this statement, as discussed before; feedback is an integral part of the formative assessment in this course. We see it a dialogue between the student and tutor rather than monolog with the student at receiving end.

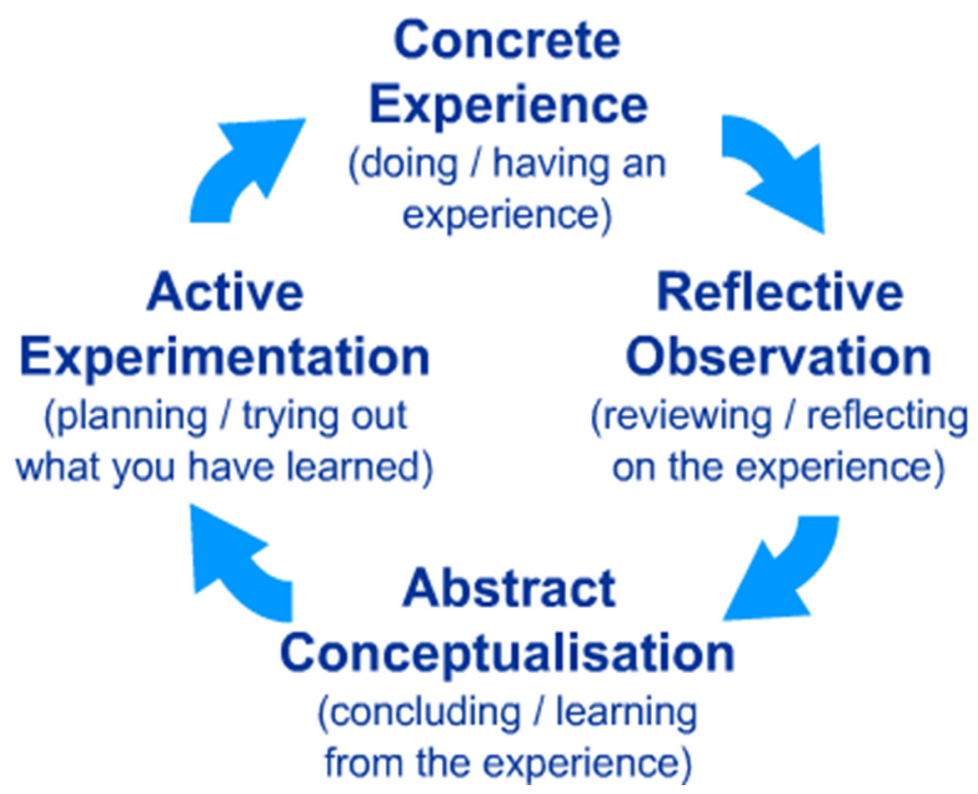

Figure 1. Kolb's Learning Cycle

Kolb (1984) proposed that learning process as a cycle. Education starts as experience-driven exercise (learning by doing) with ideas being established and fine-tuned by practice (Figure 1). The learning cycle moves through four phases:

- Concrete experience; students are allowed and encouraged to participate in new experiences.

- Reflective observation; learners reflect on their learning. In our opinion, this where the feedback feeds its vital role in this course. Feedback helps students to reflect and move around the cycle.

- Abstract conceptualization; students conceptualize, conclude and integrate ideas into their existing cognitive frameworks.

- Active experimentation; students implement and apply the concluded theories and concepts into in new situations to solve a problem.

Hill (2007) identifies the critical role of feedback in the learning cycle, by promoting reflection and considering how theory is translated into practice. The feedback loop is also clearly explained by Ashafiq in 2017 (figure 2). It is not an exaggeration when I describe feedback as "the fuel that drives and improves performance." 


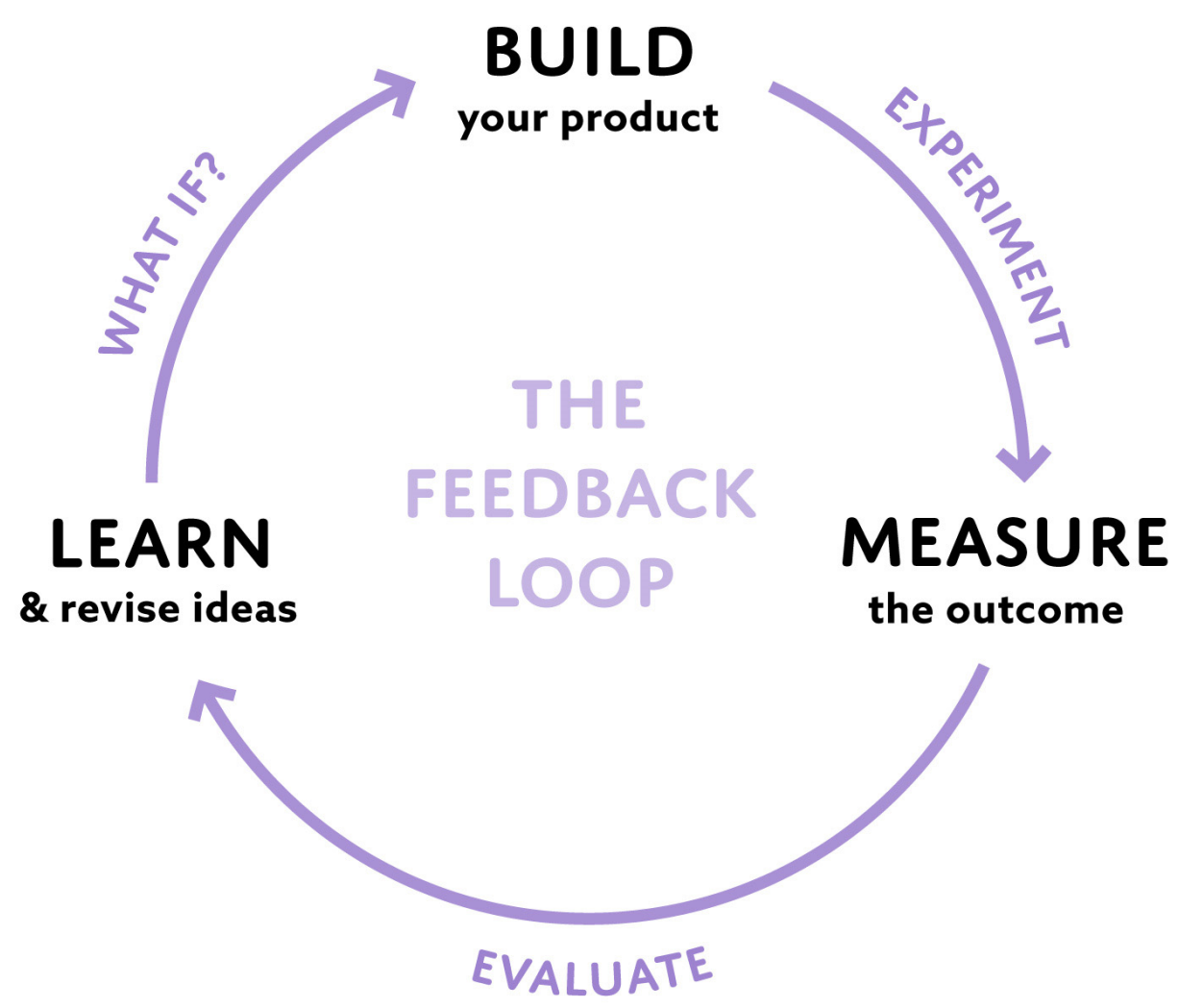

Figure 2. Feedback Loop Addapted from Ashafiq (2017)

Based on our experience in teaching and training, many students and trainees complain that they have never received feedback in spite of our awareness of the educational value of feedback. Issacson et al. (1995) and Sheehan (1984) suggested convincing explanations for this common theme. Firstly; feedback was overlooked and not given at all. Secondly; students did not realize that they have been given feedback. Thirdly; students did not recall the feedback due to lack of documentation. Another interesting study by Pelgrim et al. (2012) who demonstrated there is a disparity between the narrative feedback given to trainees, their self-reflection, and the documented action plan. Trainers' reports were generic and nonspecific revealing a big gap between the trainer and trainee in how the feedback was perceived. This study highlighted the importance of using the feedback instrument correctly as an educational tool.

\section{Feedback Strategies in the Online Master Degree in Transplantation}

In this distance-learning course, students need much more support and feedback than in a traditional course. There is a potential threat that these students feel isolated in their own online world and may not engage with this virtual educational environment properly. Implementing a robust and effective feedback mechanism allows tutors to identify and meet individual student educational needs as well as promote students to engage and progress at a high-quality level. Many feedback strategies are implemented in this course. How students are graded is clearly defined from the outset and included in the syllabus. Students should appreciate what is expected of the course and what the tutors' expectations are. They are probably taking the course for credits and grades (University of Illinois, 2013), so the number and the format of assignments, the weight each assignment carries and the due dates are made clear to the students. Also, the assessment criteria of these assignments are known up front.

Constructive feedback in this course has a framework as well as a set schedule. We provide a narrative feedback at the end of each module with the results of the assessment through the e blackboard. Alternative delivery systems for formative feedback also help in case the technical failure. For examples, computer conferencing, fax, e-mail (Curtis\& Lawson, 2001), video, Skype and Facebook (Davidson-Shivers et al. 2001). The graded coursework is returned to students as soon as possible. The course tutors are trained to provide non-judgemental and structured comments with additional sources for supplementary information where appropriate to expand the learning boundaries and add a 
reflection to the discussion (Hesketh and Laidlaw, 2002). Feedback on grades is provided in a PRIVATE communication.

The course tutors provide private and regular updates to each student on their performance. For example, contacting students praising them for their contributions to the web-based presentation encouraging them to contribute more, contacting student who is not performing well to identify and resolve the problem he/she might be facing, provision of a regular update on assignment received to date, those still outstanding and provision of regular overview on the progress of course. This helps to keep the student engaged, also gives a clear message to the students that their efforts are not wasted. Students are offered the opportunity to resubmit any substandard assignments to encourage reflection and subsequently deep learning.

The students are encouraged to have self-feedback with the self-assessment. This promotes perception and improves engagement of the student in the learning process (Sloan, 1996). Many studies showed that narrative feedback is well perceived compared to feedback in the form of numerical marks. Narrative feedback given to the students should be specific with a clear action plan (Rolfe \& Mcpherson, 1995; Shute, 2008). Tutors in this course are advised to comment on areas that can be improved rather than on personality traits, which are difficult to change. When we give negative feedback, we suggest alternative strategies. In my personal experience, using strong words "poor," "incompetence" "substandard," etc. is associated with avoidable sinking feeling which may jeopardize the perception of the whole feedback process.

We have learned from my teaching not to overload the feedback. It is recommended to identify few key messages that can be concluded and perceived well at the end. A prepared summary of the feedback (the positive aspects and areas for improvement) helps to steer the feedback process (Proctor, 2001). Formative feedback should not be exaggerated; otherwise, the message becomes diluted or even not perceived (Parsloe, 2005).

\section{Conclusion}

Constructive feedback is one of the primary drivers of education in this course. It is challenging to give feedback in distance learning due to lack of face-to-face contact, however advanced technology lends itself very well to bridge the distance and time barriers and cross the international borders. The students on this course vary in their institutional background and also differ in their experience. Considering the diversity of the students' background is essential in constructing the feedback in teaching this rapidly evolving subspecialty to be a student-tailored. This also requires efforts from tutors to be more approachable and not be restricted to the regular working hours and the national holidays to deliver a quality "anytime anywhere" education. Our approach in providing a formative education with a quality feedback has paid back by increasing the popularity of this course where there is an increase in the number of students joining the course every year (26 students in the first year, 42 students in the second year and 49 students in the third year).

\section{References}

Ashafiq, N. (2017). VALIDASI: BAGAIMANA HENDAK MENGUJI IDEA STARTUP DAN KURANGKAN RISIKO RUGI. Retrieved from: http://www.nadhir.me/validasi-bagaimana-hendak-menguji-idea-startup-dan-kurangkan-risiko-rugi/

Curtis, D., \& Lawson, M. (2001). Exploring collaborative online learning. Journal of Asynchronous Learning Networks, 5 (1).

Davidson-Shivers, G.V., Muilenburg, L.Y., \& Tanner, E. J. (2001). How do students participate in synchronous and asynchronous online discussions? Journal of Educational Computing Research, 25(4), 341-366. https://doi.org/10.2190/6DCH-BEN3-V7CF-QK47

Gordon, J. (2003). BMJ ABC of Learning and Teaching in Medicine: One to one teaching and feedback. BMJ, 326, 543-5. https://doi.org/10.1136/bmj.326.7388.543

Hesketh, E.A., \& Laidlaw, J.M. (2002). Developing the teaching instinct: feedback. Medical Teacher, 24, 245-248. https://doi.org/10.1080/014215902201409911

Hill, F. (2007). Feedback to enhance student learning: Facilitating interactive feedback on clinical skills. International Journal of Clinical Skills, 1(1), 21- 4.

Isaacson, J.H., Posk, L.K., Litaker, D.G., \& Halperin, A.K. (1995). Resident perception of the evaluation process. $J$ Gen Intern Med., 10(4 suppl), S89. 
McKimm, J. (2009). Giving effective feedback. British Journal of Hospital Medicine, 70(3), 158-61. https://doi.org/10.12968/hmed.2009.70.3.40570

Pelgrim, E. A.M., Kramer, A.W.M., Mokkink, H.G.A., \& Van der Vleuten, C.P.M. (2012). Quality of written narrative feedback and reflection in a modified mini-clinical evaluation exercise: an observational study. BMC Medical Education, 12(97), 2-6. https://doi.org/10.1186/1472-6920-12-97

Ramsden, P. (1992). Learning to Teach in Higher Education. Routledge, London. https://doi.org/10.4324/9780203413937

Reynolds, L. 20 Ways To Provide Effective Feedback For Learning Retrieved from http://www.teachthought.com/pedagogy/assessment/20-ways-to-provide-effective-feedback-for-learning/

Ries, E. (2011). The lean startup methodology. Retrieved from http://theleanstartup.com/principles

Rolfe, I., \& Mcpherson, J. (1995) Formative assessment - How am I doing? Lancet, 345, 837-839. https://doi.org/10.1016/S0140-6736(95)92968-1

Sheehan, T.J. (1984). Feedback: giving and receiving. J Med Educ., 59, 913.

Shute, V.J. (2008). Focus on formative feedback. Rev Educ Res., 78, 153-189. https://doi.org/10.3102/0034654307313795

Sloan, M. S. (1996). I love this piece because strategies to help kids evaluate their own work. Instructor, 105, 30-31.

University of Illinois. (2013). Strategies for Providing Feedback in Online Courses. Retrieved from http://www.ion.uillinois.edu/resources/tutorials/communication/feedback.asp 